\title{
Mesolithic Skull Depositions at Kanaljorden, Motala, Sweden
}

Archaeological excavations in 2009-20II at Kanaljorden in the town of Motala, Östergötland in central Sweden have unearthed a complex Mesolithic site with ceremonial depositions of human crania in a former lake. The human skulls have been treated in a complex ceremony that involved the display of skulls on stakes and the deposition of skulls in water. The rituals were conducted on a massive stone packing ( $14 \mathrm{X} \mathrm{I} 4$ $\mathrm{m}$ ) constructed on the bottom of the shallow lake (figure I).

Some human crania were found as more or less intact "skulls" (figure 2-4) while others were found as isolated fragments, for example a frontal lobe or a temporal bone. The overwhelming majority of skull elements consist of pieces of calvaria; only two mandibles have been found. Circa $75 \%$ of the crania elements can be ascribed to eleven identified persons. Nine individuals are in the age span teenage to middle age (both male and female) and the remaining two are young children, a newborn infant and a child under I 8 months. Two of the skulls had wooden stakes inserted into the cranium. In both cases the stakes were inserted the full length, from the foramen magnum to the top of the calvarium.

Besides human skulls the find material also includes a small number of post-cranial human bones and bones from animals, as well as artefacts of stone, wood, bone and antler. The artefacts include an ornamented shaft-hole pickaxe, a bone point with microblade inserts (figure 5), barbed and smooth bone points (figure 6), and antler punches. Radiocarbon analyses on human bones and wooden artefacts date the depositions to $6029-5640 \mathrm{cal} \mathrm{BC}(2 \sigma)$. The excavations are conducted by Stiftelsen Kulturmiljövård (www.kmmd.se). 


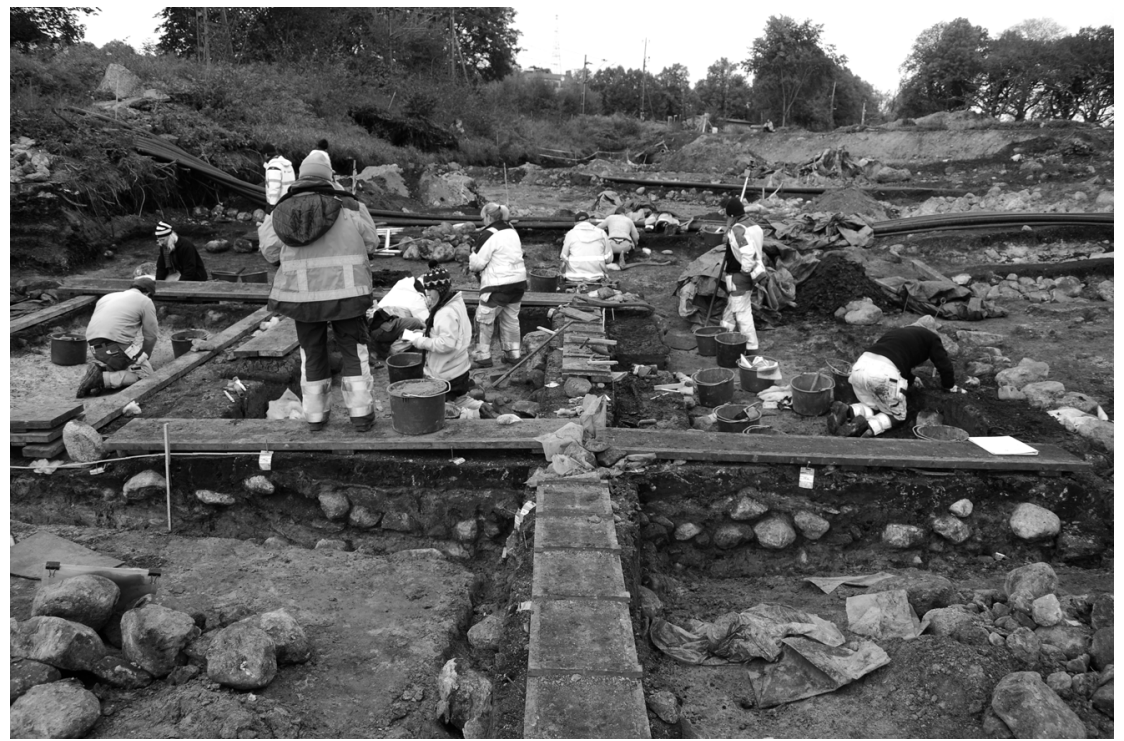

Figure I. The massive stone packing during excavation. Photo: Fredrik Hallgren.

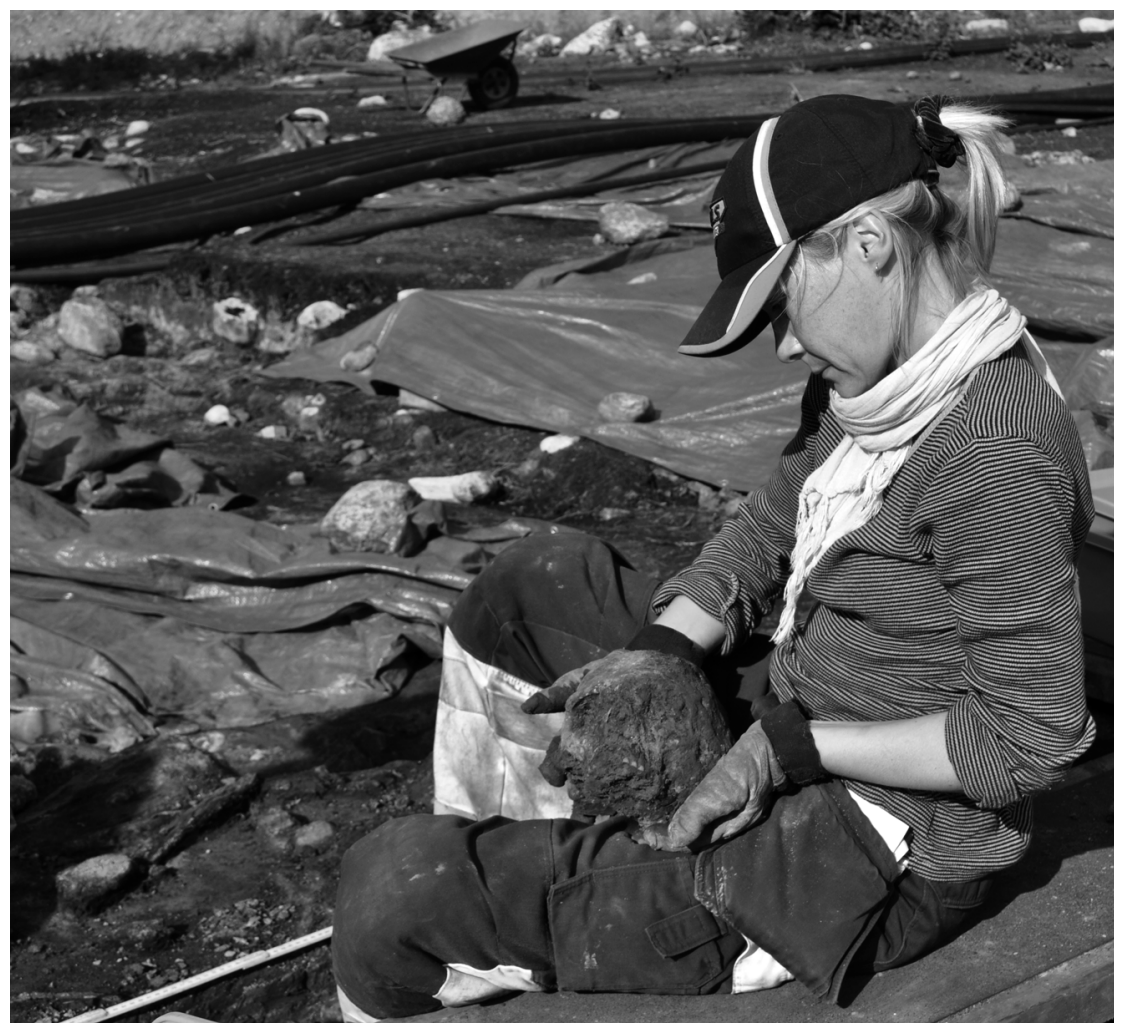

Figure 2. Tove Björk lifting a cranium. Photo: Fredrik Hallgren. 


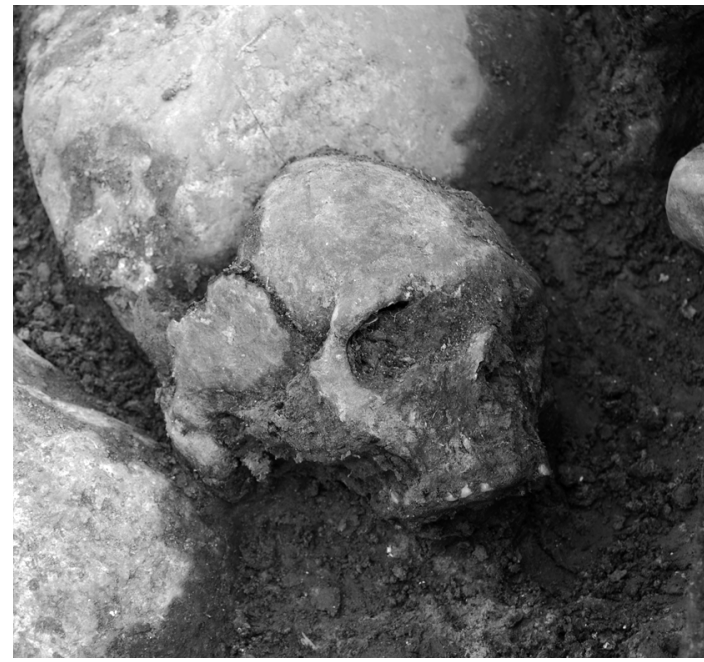

Figure 3. Female cranium. Photo: Fredrik Hallgren.

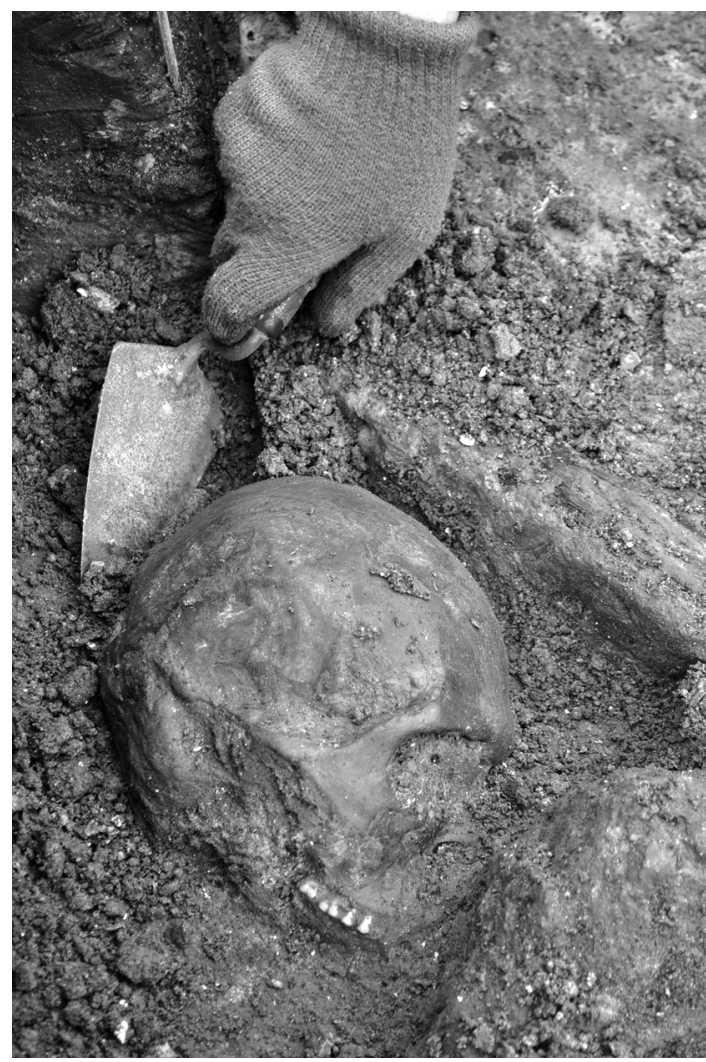

Figure 4. Cranium during excavation. Photo: Anna Arnberg.

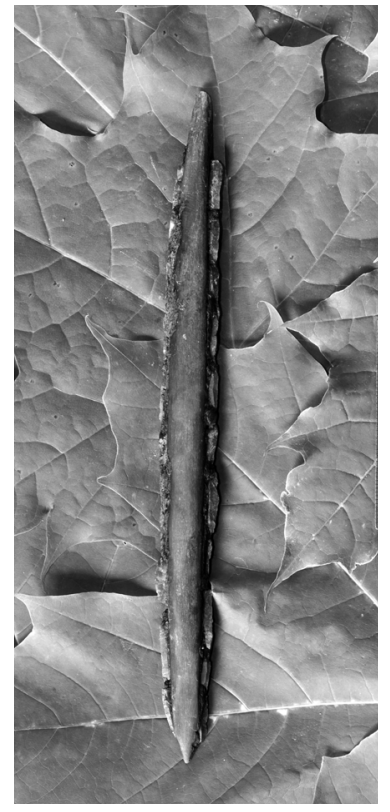

Figure 5. A bone point with microblade inserts. Photo: Fredrik Hallgren.

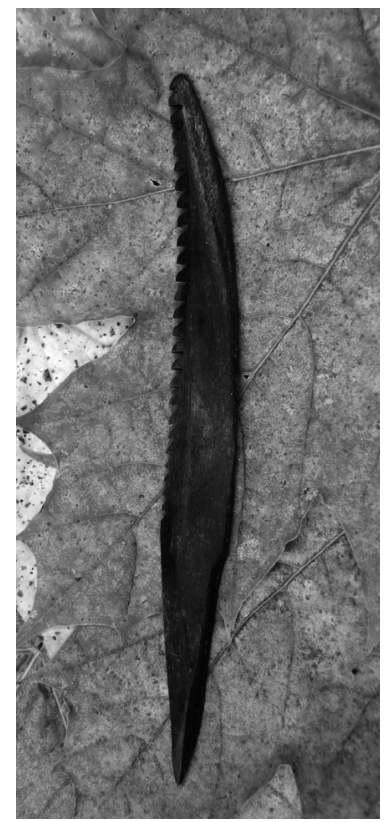

Figure 6. Bone point. Photo: Fredrik Hallgren. 